\section{Effect of color differences on elastomeric ligatures adhesion on streptococcus mutans in saliva liquid}

\author{
Baharuddin M. Ranggang, Ratna Dewi
}

CrossMark
Department of Orthodontics, Faculty of Dentistry, Hasanuddin University, Makassar, Indonesia
*Correspondence to:

Baharuddin M. Ranggang,

Department of Orthodontics, Faculty of Dentistry, Hasanuddin University,

Makassar, Indonesia

baharfkguh@gmail.com

Received: 3 January 2020 Revised: 5 February 2020

Accepted: 28 March 2020

Available Online: 1 April 2020

\title{
Abstract
}

Objective: Of this study was to determine the effect of color differences in elastomeric ligatures on the adhesion of streptococcus mutans in salivary fluid

Material and Methods: Type of research used was laboratory experimental with cross sectional study, using elastomeric ligatures 10 pieces of orthodontic elastomeric ligatures dark clear fruits. The samples were then divided into 2 groups. Each group of samples was each immersed in 100 cc of artificial saliva pH 4 which had been given each cc of streptococcus mutans and cultured in the media to see the number of colonies attached to elastomeric ligatures. The results of calculating the number of colonies were then analyzed using the SPSS version 24 program and using the Independent $t$ test with a significant value of 0.05 .

Results: The results showed that there are significant differences between the ligatures elastomeric orthodontic dark and elastomeric ligatures clear.

Conclusion: Elastomeric ligatures darker color have more adhesion to streptococcus mutans when compared to adhesion streptococcus mutans to elastomeric ligatures clear.

Keywords: Elastomeric ligatures, Streptococcus mutans, Bacterial adhesion, Saliva

Cite this Article: Ranggang BM, Dewi R. 2020. Effect of color differences on elastomeric ligatures adhesion on streptococcus mutans in saliva liquid. Journal of Dentomaxillofacial Science 5(1): 34-38. D0I: 10.15562/jdmfs.v5i1.1051

\section{Introduction}

Orthodontia is the study of the growth and development of the jaw, face and body in general that can affect the position of the teeth. Orthodontics also study the treatment of developmental disorders and bad habits, as well as efforts to keep the teeth in position after the device is removed. ${ }^{1}$

Malocclusion is the most common dental problem complained by someone, so they have the desire to take orthodontic treatment. Based on the type of orthodontic treatment is divided into three, namely removable orthodontic appliance, semifixed orthodontic appliance, and fixed orthodontic appliance. The goal of orthodontic treatment is to improve the composition and position of the teeth to obtain a stable and occlusion function, improved mastication, muscle balance and facial aesthetic harmony. Generally orthodontic treatment aims to improve the quality of life patients by overcoming psychosocial difficulties related to the appearance of the face and teeth. ${ }^{1-3}$

Orthodontic treatment from day to day id experiencing a very rapid revolution, this is evidenced by the many new materials that are starting to be used in orthodontic treatments that have different surfaces and roughness levels. But scientifically, bacterial adhesion to orthodontic treatment is an unresolved challenge. Fixed orthodontic appliances are always associated with increased plaque accumulation, bacterial colonization, and enamel decalcification. ${ }^{4,5}$

Colonization of microorganisms in the mouth due to fixed components creates an additional area of retention that facilitates bacterial colonization and causes an increase in the number of microorganisms, elastomeric ligatures are one component of fixed devices that enable the colonization of microorganisms. Components of fixed devices which are attached to the patient's teeth for approximately 1-2 years will interact with the state of the oral cavity environment which contains various species of bacteria that are commensal.,

Elastomer or binder is a component of fixed orthodontic devices which are generally made of latex material, with the advantage of high elasticity, relatively constant strength, and affordable prices. The loss of an elastomer is to absorb salivary fluid and can change shape according to temperature. Elastomers that are widely used today are amorphous polymers which have high molecular weight. One type of elastomer is elastomeric ligatures which have an important role in providing connections between orthodontic wires and bracket slots that have been developed to speed up ligation procedures and many studies have suggested that elastomeric ligatures have the potential for microorganism retention. Elastomeric ligatures 
are divided into 2 types, namely latex containing $25-40 \%$ rubber hydrocarbons (cis 1.4 polyisoprane) containing 500 units of isoprane and protein and fatty acids in small amounts. While synthetic elastomeric ligatures contain amorphous polymers from polyurethane, the specific ingredients are company secrets. A number of studies have been conducted with regard to elastomeric ligatures based on the level of bacterial colonization. However, thorough research is needed to plan further new strategies for developing more efficient tools. ${ }^{4,5}$

Imtiaz Ahmed and Rozina Nasir in Pakistan conducted a study of carious lesions in fixed orthodontic device users to find that the bacteria most responsible for dental caries were Streptococcus mutans (S.mutans) and Lactobacillus, but the main roles were Streptococcus mutans. Fang Gu, et al in 2002 conducted an analysis of Streptococcus mutans in saliva to get the number of Streptococcus mutans in saliva of children aged 2 and 16 years more than 500,000 cells / mL. Lactobacillus only plays a secondary role because it only plays a role of $0.025 \%$. One of the characteristics of Streptococcus mutans is that it has the ability to stick to all surface locations in the oral cavity, so it does not rule out the presence of bacteria attached to the surface of the elastomeric ligatures in the oral cavity. ${ }^{7-10}$

Research conducted by Sharma in India shows that some bacteria such as S. mutans and species have higher numbers found in patients with fixed orthodontic treatment than those who do not. Ravish Sharma also conducted research on bacterial colonization of elastomeric ligatures with 4 different colors and stimulated saliva from patients collected in containers to get the results that bacterial colonization depends on the color and type of material used in making elastomeric ligatures., ${ }^{4,11}$

Streptococcus mutans attachment activity (S. mutans) to the host through its receptor in this case is salivary pellicle, because salivary pellicle has several kinds of receptors for attachment to S. mutans, it is also said that salivary pellicle is a mediator of the attachment of oral bacteria on the tooth surface. Saliva specifically controls the activity of pathogenic microorganisms in the oral cavity through the regulation of salivary $\mathrm{pH} .{ }^{12}$ Based on the above, the authors are encouraged to conduct research by examining the effect of differences in the color of elastomeric ligatures on the adhesion of S. mutans in salivary fluid.

\section{Material and Methods}

Research on the effect of color differences in elastomeric ligatures on the adhesion of S. mutans in salivary fluid was conducted in September-October
2018. This research is a type of experimental laboratory research conducted in three places, namely Biochemistry Laboratory, Hasanuddin University Faculty of Mathematics for artificial saliva collection, Microbiology Laboratory Hasanuddin University Faculty of Medicine, and Oral Biology Laboratory Faculty of Dentistry, Hasanuddin University for testing up to bacterial colony counts.

This study used 10 samples of elastomeric ligatures, 5 samples of dark (black) elastomeric ligatures and 5 pieces of clear (clear) elastomeric ligatures soaked in test tubes containing artificial saliva $\mathrm{pH} 4$ as much as $100 \mathrm{cc}$ and were given the bacteria S. mutans $1 \mathrm{cc}$. Furthermore, the results of the immersion were incubated for 24 hours and then diluted with $10^{-2}$ dilution. After the dilution process, planting was carried out in the agar medium MHA (Muller Hilton Agar) and re-incubated at $37^{\circ} \mathrm{C}$ for 48 hours to see the colonies growing on the agar and finally the colony count was done using a colony counter to obtain data from the study.

\section{Results}

The research data is then processed using the SPSS 24 program. The research data are presented in tabular form as follows:

Table 1 shows the results of manually calculated colonies before processing and analysis where the dilution of $10^{-1}$ dark colored elastomeric ligatures shows the average number of $S$. mutans is 200 colonies, and $10^{-2}$ average $\mathrm{S}$. mutans colony dilutions. S. mutans dropped to 190 colonies.

While table 2 shows the results of manual calculations on dilution of $10^{-1}$ elastomeric ligatures clear shows the average number of colonies as much as $190-200$, and on $10^{-2}$ dilutions the average S. Mutans are 80-100 colonies.

Table 3 shows the results of the number of S. mutans colonies after the calculation of independent $\mathrm{t}$ test statistics obtained $\mathrm{p}$ value $=<0.001$ ( $p$ value $<0.05$ ), this indicates a significant difference between the $10^{-1}$ dilution group and the $10^{-2}$ dilution group.

Table 4 shows the results of the number of S. mutans colonies after statistical calculations of independent $t$ test obtained $p$ value $=0.047$ ( $p$ value $<0.05$ ), this shows that there is a significant difference between the clear elastomeric ligatures with dark colored elastomeric ligatures.

Table 5 shows the results of the number of S. mutans colonies after statistical calculations of the independent $t$ test on two groups of dark elastomeric ligatures and clear elastomeric ligatures. In the clear group, the value of $p=<0.001$ ( $p$ value 
Table 1 Number of S. mutans colonies in dark-colored elastomeric ligatures

\begin{tabular}{lccc}
\hline Sampel & $\begin{array}{c}\text { Total number of S. Mutans } \\
\text { bacterial colony dilution } \mathbf{~ 1 0}^{-\mathbf{1}}\end{array}$ & $\begin{array}{c}\text { Total number of S. Mutans I } \\
\text { bacterial colony dilution } \mathbf{1 0}^{-\mathbf{2}}\end{array}$ & Total \\
\hline 1 & 220 & 187 & 407 \\
2 & 200 & 140 & 340 \\
3 & 230 & 160 & 390 \\
4 & 273 & 195 & 468 \\
5 & 250 & 190 & 440 \\
Total & 1173 & 872 & 2045 \\
\hline
\end{tabular}

Table 2 Number of S. mutans colonies in clear elastomeric ligatures

\begin{tabular}{lccc}
\hline Sampel & $\begin{array}{c}\text { Total number of S. mutans } \\
\text { bacterial colony dilution } \mathbf{1 0}^{-\mathbf{1}}\end{array}$ & $\begin{array}{c}\text { Total number of S. mutans bacterial } \\
\text { colony dilution } \mathbf{1 0}^{-\mathbf{2}}\end{array}$ & Total \\
\hline 1 & 181 & 95 & 276 \\
2 & 197 & 110 & 307 \\
3 & 220 & 103 & 323 \\
4 & 180 & 81 & 261 \\
5 & 256 & 140 & 396 \\
Total & 1034 & 529 & 1563 \\
\hline
\end{tabular}

Table 3 Mean and standard deviations of the number of S. mutans colonies attached to the surface of the elastomeric ligatures based on dilution in CFU / $\mathrm{ml}$

\begin{tabular}{llll}
\hline Dilution & Mean & SD & Vallue $\mathbf{p}$ \\
\hline $10^{-1}$ & 220.70 & 31.89 & $<0.001^{*}$ \\
$10^{-2}$ & 140.10 & 42.04 & \\
\hline
\end{tabular}

${ }^{\star}$ Independent $t$ test

Table 4 Mean and standard deviations of the number of S. mutans colonies attached to the surface of the elastomeric ligatures based on the color of the elastomeric ligatures without looking at the dilution in CFU / $\mathrm{ml}$

\begin{tabular}{lccc}
\hline Group & Mean & SD & Value p \\
\hline Clear & 156.30 & 59.16 & $0.047^{\star}$ \\
Black & 204.50 & 40.03 &
\end{tabular}

${ }^{\star}$ Independent $t$ test

Table 5 Comparison of the number of S. mutans colonies attached to the surface of the elastomeric ligatures based on color groups by looking at the dilution in CFU / $\mathrm{ml}$

\begin{tabular}{lcccc}
\hline Group & Dilution & Mean & SD & Value p \\
\hline Clear & $10^{-1}$ & 206.80 & 31.92 & $<0.001^{*}$ \\
& $10^{-2}$ & 105.80 & 21.95 & $0.006^{*}$ \\
Black & $10^{-1}$ & 234.60 & 28.03 & 23.54 \\
& $10^{-2}$ & 174.40 & &
\end{tabular}

${ }^{\star}$ Independent $\mathrm{t}$ test

$<0.05)$ indicates that there is a significant difference between dilutions of $10^{-1}$ and $10^{-2}$. Meanwhile, the color group obtained $\mathrm{p}=0.006(\mathrm{p}<0.05)$, which means that there is a significant difference between dilutions of $10^{-1}$ and $10^{-2}$.
Table 6 shows the results of the number of S. mutans colonies after calculating the independent $\mathrm{t}$ test statistics based on dilution in the two groups of clear and dark colors. In dilution $10^{-1}$, the value of $\mathrm{p}=0.182(\mathrm{p}>0.05)$ showed no significant difference 
Table 6 Comparison of the number of S. mutans colonies attached to the surface of elastomeric ligatures based on dilution by looking at color groups in CFU / $\mathrm{ml}$

\begin{tabular}{lcccc}
\hline Dilution & Group & Mean & SD & Value p \\
\hline $10^{-1}$ & Clear & 206.80 & 31.92 & $0.182^{*}$ \\
& Black & 234.60 & 28.03 & \\
$10^{-2}$ & Clear & 105.80 & 21.95 & $0.001^{\star}$ \\
& Black & 174.40 & 23.54 & \\
\hline
\end{tabular}

${ }^{*}$ Independent $t$ test

between the colonies formed between the clear and dark groups. Whereas the $10^{-2}$ dilution obtained $\mathrm{p}=$ $0.001(\mathrm{p}<0.05)$, this means that there is a significant difference in the formation of $\mathrm{S}$. mutans colonies in the clear elastomeric ligatures group and the dark color elastomeric ligatures group.

\section{Discussion}

Fixed orthodontic treatment is now widely known among the wider community, both adults and children many who use orthodontics for dental and oral care. One component of fixed devices used during orthodontic treatment is elastomeric ligatures (power $\mathrm{O}$ ) which can be an additional habitat for colonization of pathogenic microorganisms, including $\mathrm{S}$. mutans which is the main cause of dental caries formation. Elastomeric ligatures are very much sold in the market with a variety of different colors, thus allowing people to freely choose the desired color. ${ }^{3,13}$

Based on research conducted by Sharma $\mathrm{R}$ et al. ${ }^{11}$ it was suggested that bacterial colonization depends on the type of color and material used in making elastomeric ligatures. In that study, Sharma $\mathrm{R}$ et al. ${ }^{11}$ used 4 different colors of elastomeric ligatures namely superslick, clear, blue, and pink and got the result that there was more bacterial adhesion to pink elastomeric ligatures than other elasto-meric ligatures. ${ }^{11}$

In this study, two colors of elastomeric ligatures were tested, namely elastomeric ligatures (clear) and elastomeric ligatures (black) with the same brand to see the adhesion of Streptococcus mutans in both samples. This research was conducted in three places, namely the Biochemical Laboratory of the Faculty of Mathematics and Natural Sciences, Hasanuddin University for the collection of artificial saliva, the Laboratory of Microbiology of the Faculty of Medicine, Hasanuddin University, and the Oral Biology Laboratory of the Faculty of Dentistry, Hasanuddin University for bacterial culture and the calculation of bacterial colonies.

Based on the table, the results of statistical tests show a significant correlation of Streptococcus mutans colonies between clear elastomeric ligatures and dark colored elastomeric ligatures, this is because $(\mathrm{p}<0.05)$, with $\mathrm{p}=0.47$ based on sample groups without looking at dilution. Whereas if seen from the sample group with each dilution obtained $(p<0.05)$, that is in the clear elastomeric ligatures group $\mathrm{p}=<0.001$, while in the dark color elastomeric ligatures group is obtained $\mathrm{p}=0.006$ which means that in the dark colored elastomeric ligatures group has more adhesion of S. mutans compared to the clear elastomeric ligatures group. ${ }^{14}$

This is in accordance with research conducted by Sharma $\mathrm{R}$ et al. ${ }^{11}$ found that $\mathrm{S}$. mutans bacteria formed colonies in colored areas more than clear.

\section{Conclusion}

There is an effect of differences in the color of elastomeric ligatures on the adhesion of $\mathrm{S}$. mutans in salivary fluid. Black elastomeric ligatures have more S. mutans adhesion compared to S. mutan adhesions on clear elastomeric ligatures

\section{Acknowledgment}

None.

\section{Conflict of Interest}

The authors report no conflict of interest.

\section{References}

1. Goenharto S, Elly R, Nurul IK. Comparison between removable and fixed orthodontic retainers. J Vocat Health Stud 2017;1: 82-87.

2. Marlisa W. Differences in dental plaque scores, salivary $\mathrm{pH}$ and oral hygiene status between users and non-orthodontic users. J Kesehatan Masy 2017;5: 114. (In Indonesia)

3. Alawiyah T. Complications and risks related to orthodontic treatment. J Ilmiah Widya 2017;4: 256-261. (In Indonesia)

4. Shirozaki MU, Ferreira JTL, Kuchler EC, et al. Quantifivation of streptococcus mutans in different types of ligature wire and elastomeric chains. Braz Dent J 2017;28: 498-503.

5. Sawhney R, Sharma R, Sharma K. Microbial colonization on elastomeric ligatures during orthodontic therapeutics: an overview. Turkish J Orthod 2018;31: 21-25. 
6. Siwy CJ, Tendean LEN, Anindita PS. Metal chromium (Cr) and nickel $(\mathrm{Ni})$ release test for several brands of stainless steel bracket in artificial saliva fluid. Jurnal e-Gigi 2015;3: 422. (In Indonesia)

7. Ahmed I, Saif-ul-Haque, Nasir R. Carious lession in patients undergoing orthodontic treatment. J Pakistan Med Assoc 2015;61: 1176-1177.

8. Gu F, Renate L, Anderson MH, et al. Analisesod streptococcus mutans in saliva with species-species monoclonal antibodies. Hybrid Hybridomics 2014;21: 225-226.

9. Esia D, Man A, Burlibasa L, et al. Salivary level of streptococcus mutans and lactobacillus spp. related to a high a risk of caries disease. Rom Biotech Lett 2017;22: 12496-12497.

10. Fatmawati DWA. Relationship of streptococcus mutans biofilms to the risk of dental caries. J Kedokteran Gigi Unej Stogmatog 2011;8: 128. (In Indonesia)

11. Sharma R, Sharma K, Sawhney R. Evidence of variable colonization on coloured elastomeric ligatures during orthodontic treatment: an intermodular comparative study. J Clin Exp Dent 2018;10: 271-278.
12. Anggreani A, Yuliati A, Nirwana I. Attachment of streptococcus mutans colony on the surface of a visible composite resin. Majalah Kedokteran Gigi 2005;38: 8-11. (In Indonesia)

13. Gani BA. Changes in the $\mathrm{pH}$ of artificial saliva after integration with candida albicans, streptococcus mutans, and aggregatibacter actiomycetemcomitans. J Kedokteran Gigi Cakradanya 2013;5: 542-618. (In Indonesia)

14. Nahusona DR, Meydina A. Identification of dominant aerob bacteri in saliva of the patient with fixed ortodontic appliance. J Dentomaxillofac Sci 2018;3: 96-99.

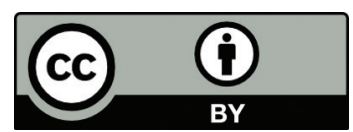

This work is licensed under a Creative Commons Attribution 